\title{
On the Prediction of Critical Temperatures of Ionic Liquids: Model Development and Evaluation
}

\author{
Mehdi Sattari, ${ }^{*}, a$, Arash Kamari, ${ }^{a}$ Amir H. Mohammadi, ${ }^{*, a, b}$ Deresh Ramjugernath,*,a \\ ${ }^{a}$ Thermodynamics Research Unit, School of Engineering, University of KwaZulu-Natal, Howard College Campus, \\ King George V Avenue, Durban 4041, South Africa \\ ${ }^{b}$ Institut de Recherche en Génie Chimique et Pétrolier (IRGCP), Paris Cedex, France
}

\begin{abstract}
In this study, the Guggenheim equation was used to estimate the critical temperature $\left(T_{c}\right)$ of 106 ionic liquids using experimental surface tension data as inputs. A group contribution (GC) and a Quantitative Structure-Property Relationship (QSPR) model were also developed to correlate/predict the $T_{c}$ of ionic liquids. It was shown that a lack of sufficiently large database for $T_{c}$ lead to the development of models with low prediction capability. The model's output as well as the $T_{c}$ values estimated from the surface tension data were compared with the critical temperatures calculated by the Valderrama et al. method. The results showed that the Valderrama et al. method produces different data values compared with the values calculated by the Guggenheim equation. Neither the GC, QSPR, nor Valderrama's method is capable of reliable prediction of the $T_{c}$ of ionic liquids. Consequently, the calculated $T_{c}$ values are not reliable enough to be used in the development of corresponding state models for prediction of other thermophysical properties of ionic liquids. Any usage of critical properties of ionic liquids should be done with a serious caution.
\end{abstract}

Keywords: Critical Temperature, $\mathrm{T}_{\mathrm{c}}$, Ionic Liquid, Group Contribution, GC, QSPR, Model.

*Corresponding authors: Email: $\underline{\text { sattarim@ukzn.ac.za, }}$ a.h.m@irgcp.fr, and ramjuger@ukzn.ac.za 


\section{Introduction}

Over the last few decades, researchers from around the world have undertaken numerous studies on ionic liquids (ILs) and demonstrated their potential use in various industrial applications. Ionic liquids are defined as molten salts which are generally liquid at or near room temperature (typically below $100{ }^{\circ} \mathrm{C}$ ) due to the poor coordination of ions [1]. In general, they show unusual, but interesting properties such as extremely low saturation vapor pressure and negligible volatility, wide liquidus range, nonflammability, high thermal conductivity, and high physical and chemical stability [2]. These unique properties make them potential replacement solvents for conventional volatile and commonly toxic and flammable organic solvents in numerous industrial applications such as extraction and separation processes [3-5], battery industry [6, 7], solar panels [8, 9], waste recycling [10, 11], lubricants [12-15], fuel cells [16, 17], polymer and biopolymer processing [18-20], electroplating [21, 22], gas separation and $\mathrm{CO}_{2}$ capturing [23-30], catalysis [31-33], and other processes [34-37].

In order to understand the behaviour of ILs in such applications, thermodynamic models and property estimation methods are required. The critical properties, especially the critical temperature $\left(T_{c}\right)$, are used commonly in the development of the corresponding state models. The critical temperature of a substance is the temperature at and above which vapor of the substance cannot be liquefied, no matter how much pressure is applied. The behavior of a fluid near its critical point is a specific property necessary to develop the thermodynamic models for fluids [38]. Due to presence of high electrostatic interactions and Coulombic forces, as well as short-range van der Waals interactions in ionic liquids, the critical properties of ionic liquids, cannot be measured as they are decomposed before their normal boiling temperature $\left(T_{b}\right)$ are reached $[39,40]$. As a result, experimental data of critical properties of ILs as well as their $T_{b}$ are not available in the literature and they can only be estimated in theory. 
Despite this limitation for the ionic liquids, some researchers have tried to use the available correlations and estimation methods of common organic compounds to estimate the critical properties of ILs. The most accepted approach is to use the relationship between critical temperature, density, and surface tension and thereafter, estimate the $T_{c}$ of ionic liquids. According to the fact that the surface tension becomes zero at the critical temperature, two correlations were presented by Eötvos [41] and Guggenheim [42] which are shown in equation (1) and equation (2), respectively.

$\gamma\left(\frac{M}{\rho}\right)^{2 / 3}=k\left(T_{c}-T\right)$

$\gamma=K\left(T_{c}-T\right)^{11 / 9}$

where $\gamma$ is surface tension, $\rho$ is density, $M$ is molar mass, $k$ and $K$ are two different constants. These equations usually can estimate the $T_{c}$ of organic compounds pretty well; so it is assumed that they are applicable for ionic liquids too. This approach has been followed by the majority of researchers [38, 40, 43-47] to calculate and report the critical temperature of ionic liquids.

Another approached was followed by Valderrama et al. [39] where they used the Lydersen group contribution method to estimate the critical pressure and critical volume, and the Joback and Reid group contribution method to calculate the normal boiling temperature and the critical temperature of ionic liquids. They combined the best results of Lydersen's method with the best results of the Joback-Reid method to propose a "modified Lydersen-Joback-Reid" method and stated that this modified method had good results for molecules of high molecular weight. Thereafter, Valderrama at al. performed a consistency test and used a correlation for density to validate the estimated critical properties of ionic liquids. This correlation was developed earlier by Valderrama and Abu-Sharkh [48] to relate the critical 
properties of saturated liquids and petroleum fractions to their density. Consequently, they published the results of their calculations for 1130 ionic liquids [49].

Despite their interesting approach, there is unsatisfactory agreement between the values of $T_{c}$ estimated by their method and the approach using Guggenhiem equations for most of the ionic liquids. Nonetheless, these calculated critical properties were used by several researchers to develop corresponding state models for prediction of thermophysical properties of ionic liquids [50-57].

In this study, the available experimental data of surface tension of ionic liquids were used to estimate the critical temperature. Thereafter, a group contribution (GC) and a Quantitative Structure-Property Relationship (QSPR) models were developed to correlate/predict the $T_{c}$ of ionic liquids. The results were compared with the values calculated by Valderrama et al.

\section{Model Development Methodology}

\subsection{Data preparation}

The NIST Standard Reference Database \#103b [58] and some newly published papers [59-63] were used to extract experimental data for surface tension of ionic liquids. In the next step, the data gathered were analyzed and screened to remove duplicates and outliers. As the surface tension is temperature dependent, data analysis was undertaken as follows:

1) Where there were several reported values of the desired property for a single temperature, the values were plotted against temperature to find and remove the sources that their results had no agreement with others. 
2) If there were only two sources, the values with the lowest uncertainty were incorporated into dataset utilized.

3) If the reported values had equal uncertainties, the latest published values were utilized.

4) To verify the potential outliers in the final dataset, the target values were plotted against temperature and a (non-)linear curve fitting algorithm was applied to fit the data. The data points which were "far" from the curve fitted were considered as outliers and omitted from the dataset.

The result of the screening process was 1513 data points for 139 ionic liquids constituted from 63 types of cations and 40 types of anions. Figure 1 shows the number of ionic liquids in each family. In addition, the names and structures of cations and anions are available in Table S1 and Table S2 in the supplementary materials.

\section{Figure 1}

\section{2 $T_{c}$ Calculation}

As mentioned before, the most realistic value of critical temperature should be calculated from the Eötvos and/or Guggenheim equations. Previous studies $[38,40]$ showed that the $T_{c}$ calculated by these equations are in fair agreement with each other (less than $100{ }^{\circ} \mathrm{C}$ in most cases); however the Eötvos equation is more prone to deviations due to use of two sources of experimental data as inputs (surface tension and density). In addition, it is difficult to find experimental data for surface tension and density measured by the same laboratories at the same conditions. As a result, the Guggenheim equation was chosen for the estimation of critical temperature of ionic liquids. Unfortunately, for 33 ILs there was only one data point available and thus the $T_{c}$ could not be calculated for them. Consequently, the critical temperature was calculated for 106 ionic liquids. 


\subsection{Model Development}

The GC and QSPR approaches were followed in the development of the models. The common approach in GC modeling is to use the linear summation of functional groups to develop a model. This approach is beneficial because of its simplicity, but its disadvantage is the weakness in the prediction of properties for compounds which exhibit complex behavior, have isomers, etc. [64-70]. The Quantitative StructureProperty Relationship is a well-established and highly respected technique to correlate diverse simple and complex physicochemical properties of a component by its molecular structure and interactions among different molecular groups based on their connectivities [71-73]. In this approach, it is assumed that the molecular features which are called "molecular descriptors" affect directly the properties of compounds. As a result, there are some descriptors which can deal with isomers and proximity effects (inter/intramolecular interactions). This feature is the most important advantage of the QSPR method over the GC method. In addition, QSPR models usually have less parameters than GC models for a similar accuracy, which indicates that the descriptors can correlate the target property better than simple functional groups $[68-70,72,74]$.

To calculate the functional groups as well as the descriptors, the SMILES formula of cations and anions were used separately and the functional groups and 2D descriptors were calculated using Dragon software [75]. After calculating the structure-based variables for the cations and anions, they were collected into one dataset; two prefixes were added to the name of GCs/descriptors to make the cations and anions variables distinguishable. For the QSPR model development, pair correlation was undertaken for all descriptors. Accordingly, pairs of descriptors with a correlation coefficient greater than 0.9 were removed and the remainders used in the model development [73].

As the final step of model development, the experimental data was divided in two subsets. One was used to develop and train the model which is named the training set, the other for determining the prediction capability of the model for new compounds which were not used in model development (training set). For 
this purpose, $\mathrm{K}$-means clustering is used to select the training and test sets. $\mathrm{K}$-means clustering is a method of cluster analysis which aims to partition $n$ observations into $k$ clusters in which each observation belongs to the cluster with the nearest mean. As a result, 20\% of the ILs were kept for the test set and remainder used as the training set to develop the model.

\section{Results and discussion}

To assess the possibility of developing a predictive model for estimating the $T_{c}$ of ionic liquids, a 30parameter GC and a 25-parameter QSPR models were developed. The GC model has an Average Absolute Relative Deviation (AARD) of $5.17 \%$ for the 106 data points, and the QSPR model has an AARD\% of $4.69 \%$ (Table 1). As a result, the models can calculate the training set and predict the test set fairly well. The models parameters as well as their outputs are available in the supplementary materials.

To compare the model output for other ionic liquids, the $T_{c}$ for 33 additional ionic liquids were calculated. As mentioned before, these ionic liquids had only one experimental surface tension data point; so it was not possible to fit the Guggenheim equation and find these critical temperature. Table 2 shows the outputs of the GC and QSPR models for these ionic liquids. Unfortunately, Valderrama et al. did not report the coefficients for the functional groups in their published paper [49] and it was therefore not possible to calculate the $T_{c}$ for these ionic liquids. The $T_{c}$ of only some of them were reported by Valderrama et al.

As seen in Table 2, for some of the ionic liquids there is an agreement between the GC, QSPR, and Valderrama et al. methods, e.g. 1-hexyl-3-methylimidazolium nitrate. On the other hand, the $T_{c}$ of some ionic liquids calculated by the GC and QSPR models are similar, but different from that obtained by Valderrama's method, e.g. 1-ethyl-3-methylimidazolium acetate; and some are altogether different for all methods, e.g. 1-ethyl-3-methylimidazolium bis[(pentafluoroethyl)sulfonyl]amide. The worst agreement amongst methods are for ionic liquids with bis[1-methylimidazolium] cations. The outputs of the GC and 
QSPR models are different values and the trends are also not similar. In addition, the GC model produces negative values of $T_{c}$ which are obviously meaningless and erroneous. In these cases, the QSPR model has better output compared with the GC model, but the trends are still not acceptable.

For ionic liquids with 3,3'-(1,10-decanediyl)bis[1-methylimidazolium] as the cation and bis(trifluoromethylsulfonyl)imide $\quad$ (AKA 1,1,1-trifluoro-N-[(trifluoromethyl)sulfonyl] methanesulfonamide) and tetrafluoroborate, and as the anion, the values of $T_{c}$ are $915.6 \mathrm{~K}, 964.9 \mathrm{~K}$ respectively; but for the 1,1,2,2,2-pentafluoro-N-[(1,1,2,2,2-pentafluoroethyl)sulfonyl] ethanesulfonamide (AKA bis(pentafluoroethylsulfonyl)imide) anion, the $T_{c}$ is calculated as $1961.2 \mathrm{~K}$ by the QSPR model. According to Table S2 in supplementary materials, the later has four additional fluorine atom compared with bis(trifluoromethylsulfonyl)imide anion; but the molecular structures are similar. In addition, the surface tension of these two ionic liquids does not have a noticeable different at the same temperature (less that $8 \%$ ); so this small difference in their surface tension cannot lead to $1000 \mathrm{~K}$ jump in the critical temperature estimation. For this ionic liquid, the GC model produces a negative value $(-825.86 K)$, as mentioned before. As a result, it is concluded that both model fails to estimate the $T_{c}$ of this ionic liquid due to lack of experimental surface tension data and consequently, its absence in training set. Similar effect is observed for other ionic liquids with abovementioned anion as there is not any surface tension data for them; however the temperature jump is less than $500 \mathrm{~K}$.

As the number of data points used in the model development procedure is not large enough, it is not possible to develop a model with a wide range of applicability and high prediction ability. Large deviations are expected and inevitable and currently it is not possible to develop a quality model with the available experimental datasets for surface tension.

To check the validity of the Valderrama's method, the values of $T_{c}$ calculated by the Guggenheim equation and the outputs of the GC model as well as QSPR were compared with the Valderrama et al. 
values in the supplementary materials. According to the data provided, the comparison can be done for only 51 ionic liquids because the coefficients for functional groups are not available for Valderrama's model [49]. Regarding to Figure 2, it is clear that most of the $T_{c}$ values calculated by Valderrama's method do not agree with the values calculated using the surface tension data.

\section{Figure 2}

The results provided in the supplementary materials can be visualized for specific cations and different anions. For example, Figure 3 shows the critical temperatures calculated by the Guggenheim equation, GC, QSPR, and Valderrama's methods for 1-ethyl-3-methylimidazolium ionic liquids. Accordingly, Valderrama's $T_{c}$ values do not have agreement with other models. In addition to the deviations in the values of $T_{c}$, the model also fails to estimate the $T_{c}$ in a reasonable trend according to the output of Guggenheim equation.

In another comparison, the $T_{c}$ values of 1-butyl-3-methylimidazolium ionic liquids are compared and the results are shown in Figure 4. Accordingly, similar fluctuations are observed in Valderrama's model which indicates the disagreement with the Guggenheim model.

\section{Figure 3}

\section{Figure 4}

As discussed earlier, the QSPR model developed is more reliable than the GC model as the later calculates negative $T_{c}$ values for some ionic liquids. Thus, the QSPR model is chosen to calculate the $T_{c}$ for 1130 ionic liquids which were used by Valderrama et al. [49]. According to the data provided in the supplementary materials, there are some ionic liquids for which the QSPR model produces negative or very high values of $T_{c}$. As discussed before, it is not possible to develop a comprehensive model using 
such a small number of data points. In this study, the QSPR model has been developed using 41 cations and 34 anions, while Valderrama's database consists of 484 cations and 113 anions. It is thus expected that the QSPR model developed would not be reliable for calculation of values for some ionic liquids as their cation and/or anion have not been used in the "training" subset.

To have a better comparison, the calculated $T_{c}$ of 1-ethyl-3-methylimidazolium ionic liquids with 45 different anions is shown in Figure 5. According to Figure 3, the average critical temperature of 1-ethyl-3methylimidazolium ionic liquids is approximately $1200 \mathrm{~K}$, which is shown by a red tie line in Figure 5. Accordingly, the QSPR model provides similar results and only four deviations are observed; two for around $700 \mathrm{~K}$ and two for over $1800 \mathrm{~K}$. Valderrama's model has more fluctuations between $600 \mathrm{~K}$ and $1000 K$. Despite the better results for the QSPR model proposed, both models seem to be not reliable enough for use in developing accurate corresponding state models; however the QSPR model seems to have better predictions for the ionic liquids for which their cation and anion exist in the "training" set.

\section{Figure 5}

For further comparison, the effect of side-chain length on the $T_{c}$ value is investigated for a certain anion and cation core. Rebelo et al. [40] used both Guggenheim and Eötvos equations and calculated the critical temperatures for 15 1-alkyl-3-methylimidazolium ionic liquids with different anions. They observed that the longer side-chain imidazolium ionic liquids had lower critical temperature. They interpreted that longer side-chains in the 1-alkyl-3-methylimidazolium cation decreased the relative importance of the Coulomb forces which led to the smaller values of $T_{c}$. In another study, Zaitsau et al. [76] measured the vapor pressure of four 1-alkyl-3-methylimidazolium bis(trifluoromethylsulfonyl)imide ionic liquids and used the Antoine equation to extrapolate the vapor pressure data to atmospheric pressure and estimated the $T_{b}$ of ionic liquids studied. They also observed the same decrease in $T_{b}$ while the length of side-chain 
was increased. As the $T_{b}$ of majority of chemical compounds lie around 0.6 of $T_{c}$, it can be concluded that their work confirmed the Zaitsau et al. interpretation.

In this regard, the effect of aliphatic side-chain length for 1-alkyl-3-methylimidazolium ionic liquids with bis[(trifluoromethyl)sulfonyl]amide and chloride anions are shown in Figure 6 and Figure 7, respectively. Regarding to these figures, the Guggenheim equation and QSPR model show a decrease in $T_{c}$ while the length of side-chain increases. On the contrary, Valderrama's model shows an increase in $T_{c}$ proportional to the length of side-chain, which opposes the abovementioned findings. This incompatible behavior is due to the nature of compounds used by Valderrama et al. to develop their models. As mentioned before, they have used high molecular weight (non-ionic) compounds to develop the models in which the $T_{b}$ and consequently, $T_{c}$ increases proportionally to the side-chain length and molecular weight of compounds. As a result, Valderrama's model produces inaccurate $T_{c}$ values which should be considered if one wants to use this model to estimate the critical temperature of ionic liquids.

\section{Figure 6}

\section{Figure 7}

According to the papers published by Valderrama et al. [39, 49, 77], a density correlation was used to validate the calculated critical properties and normal boiling points of ionic liquids which had been developed for saturated liquids and petroleum fractions [48].

$$
\begin{aligned}
& \rho=\left(\frac{A}{B}\right)+\left(\frac{2}{7}\right)\{(A \operatorname{Ln} B) / B\} \frac{T-T_{b}}{T_{c}-T_{b}} \\
& A=a+b M / V_{c} \\
& B=\left(\frac{c}{V_{c}}+\frac{d}{M}\right) V_{c}^{\delta}
\end{aligned}
$$


$a=0.3411, \quad b=2.0443, \quad c=0.5386$

$d=0.0393, \quad \delta=1.0476$

It was reported that the density calculated using the above-mentioned correlation had an average deviation of less than $19 \%$. As a result, Valderrama et al. concluded that the estimated critical properties as well as the normal boiling point were valid and reliable. In this study, it was shown that the critical temperatures calculated by Valderrama's model were mostly doubtful compared with the $T_{c}$ calculated using the experimental surface tension of ionic liquids. Thus, the estimated $T_{b}, V_{c}$, other critical properties, and the validation technique could be questionable and these data should be used with great care.

In recent years, some corresponding state models [50-57] have been developed by several researchers to model other thermophysical properties of ionic liquids using the critical properties estimated by Valderrama et al. models. According to the results of this study, these models are also questionable and should be used with great care. The development of models for critical properties of ionic liquids and use of them for subsequent development of corresponding state models therefore needs more research and consideration. Moreover, the estimation of the critical temperature of ionic liquids using surface tension data is highly dependent on the quality of measurements and uncertainty of surface tension data. In addition, further model development requires larger datasets of experimental data for surface tension. At this time, large reliable datasets for surface tension are lacking, which limits the development of models in term of prediction reliability.

\section{4- Conclusions}

The theoretical critical temperature of ionic liquids was calculated using experimental data for surface tension of ionic liquids by means of the Guggenheim equation. Thereafter, two different GC and QSPR models were developed to assess the prediction ability of the models and compare the results with the 
pioneering work of Valderrama et al. [39, 49, 77]. This study showed that the QSPR model provided better results compared with the GC model in terms of prediction and meaningful results. In addition, it was shown that the critical temperatures calculated by Valderrama's model had relatively large deviations compared with values estimated from surface tension data. Furthermore, Valderrama's model failed to represent the effect of side-chain length on critical temperature of ionic liquids. Consequently, one can question the validation method used by Valderrama et al. and thus one can conclude that the reported critical properties are probably not of suitable reliability to be used for developing corresponding state models for different thermophysical properties of ionic liquids.

\section{Acknowledgement}

The authors would like to thank Dr. Michael Frenkel of the National Institute of Standards and Technology for providing the NIST Standard Reference Database. This work is based upon research supported by the South African Research Chairs Initiative of the Department of Science and Technology and National Research Foundation. 


\section{References}

[1] G. Wypych, Handbook of Solvents, ChemTec Publishing, Toronto, 2001.

[2] J.R. Bell, H. Luo, S. Dai, Superbase-derived protic ionic liquid extractants for metal ion separation, Sep. Purif. Technol.

[3] B. Mokhtarani, J. Musavi, M. Parvini, Extraction of toluene from alkane using [Bmim][NO3] or [Omim][NO3] ionic liquid at 298.15 K and atmospheric pressure, Fluid Phase Equilib., 363 (2014) 41-47.

[4] B. Rodríguez-Cabo, A. Arce, A. Soto, Desulfurization of fuels by liquid-liquid extraction with 1ethyl-3-methylimidazolium ionic liquids, Fluid Phase Equilib., 356 (2013) 126-135.

[5] M. Larriba, P. Navarro, J. García, F. Rodríguez, Liquid-liquid extraction of toluene from n-heptane by $\{[\mathrm{emim}][\mathrm{TCM}]+[\mathrm{emim}][\mathrm{DCA}]\}$ binary ionic liquid mixtures, Fluid Phase Equilib., 364 (2014) 48-54.

[6] A. Lewandowski, A. Świderska-Mocek, Ionic liquids as electrolytes for Li-ion batteries-An overview of electrochemical studies, J. Power Sources, 194 (2009) 601-609.

[7] S. Menne, J. Pires, M. Anouti, A. Balducci, Protic ionic liquids as electrolytes for lithium-ion batteries, Electrochem. Commun., 31 (2013) 39-41.

[8] V. Jovanovski, V. González-Pedro, S. Giménez, E. Azaceta, G. Cabañero, H. Grande, R. Tena-Zaera, I. Mora-Seró, J. Bisquert, A Sulfide/Polysulfide-Based Ionic Liquid Electrolyte for Quantum DotSensitized Solar Cells, J. Am. Chem. Soc., 133 (2011) 20156-20159.

[9] G.-H. Kim, H.-B. Kim, B. Walker, H. Choi, C. Yang, J. Park, J.Y. Kim, Effects of Ionic Liquid Molecules in Hybrid PbS Quantum Dot-Organic Solar Cells, ACS Appl. Mater. Interfaces, 5 (2013) $1757-1760$.

[10] M.T. Hamed Mosavian, Z. Es'haghi, N. Razavi, S. Banihashemi, Pre-concentration and determination of amitriptyline residues in waste water by ionic liquid based immersed droplet microextraction and HPLC, J. Pharm. Anal., 2 (2012) 361-365.

[11] X. Zeng, J. Li, H. Xie, L. Liu, A novel dismantling process of waste printed circuit boards using water-soluble ionic liquid, Chemosphere, In Press (2013).

[12] M. Uerdingen, Ionic Liquids as Lubricants, in: P.T. Anastas (Ed.) Handbook of Green Chemistry, Wiley-VCH Verlag GmbH \& Co. KGaA, 2010, pp. 203-219.

[13] V. Khare, M.-Q. Pham, N. Kumari, H.-S. Yoon, C.-S. Kim, J.-I.L. Park, S.-H. Ahn, Graphene-Ionic Liquid Based Hybrid Nanomaterials as Novel Lubricant for Low Friction and Wear, ACS Appl. Mater. Interfaces, 5 (2013) 4063-4075.

[14] B.A. Kheireddin, W. Lu, I.C. Chen, M. Akbulut, Inorganic nanoparticle-based ionic liquid lubricants, Wear, 303 (2013) 185-190.

[15] A. Somers, P. Howlett, D. MacFarlane, M. Forsyth, A Review of Ionic Liquid Lubricants, Lubricants, 1 (2013) 3-21.

[16] R.F. de Souza, J.C. Padilha, R.S. Gonçalves, J. Dupont, Room temperature dialkylimidazolium ionic liquid-based fuel cells, Electrochem. Commun., 5 (2003) 728-731.

[17] B. Lin, L. Qiu, J. Lu, F. Yan, Cross-Linked Alkaline Ionic Liquid-Based Polymer Electrolytes for Alkaline Fuel Cell Applications, Chem. Mater., 22 (2010) 6718-6725.

[18] D. Holbrey John, J. Chen, B. Turner Megan, P. Swatloski Richard, K. Spear Scott, D. Rogers Robin, Applying Ionic Liquids for Controlled Processing of Polymer Materials, in: Ionic Liquids in Polymer Systems, American Chemical Society, 2005, pp. 71-87.

[19] M.H. Luke, P.F. Matthew, E.K. Brown, M.F. Douglas, C.D.L. Hugh, C.T. Paul, Natural Fiber Welding: Ionic Liquid Facilitated Biopolymer Mobilization and Reorganization, in: Ionic Liquids: Science and Applications, American Chemical Society, 2012, pp. 145-166.

[20] P.K. Singh, B. Bhattacharya, R.K. Nagarale, K.-W. Kim, H.-W. Rhee, Synthesis, characterization and application of biopolymer-ionic liquid composite membranes, Synth. Met., 160 (2010) 139-142. [21] Q.X. Liu, S.Z. El Abedin, F. Endres, Electroplating of mild steel by aluminium in a first generation ionic liquid: A green alternative to commercial Al-plating in organic solvents, SuCT, 201 (2006) 13521356. 
[22] A.P. Abbott, G. Frisch, K.S. Ryder, Electroplating Using Ionic Liquids, Annu. Rev. Mater. Res., 43 (2013) 335-358.

[23] D. Camper, J.E. Bara, D.L. Gin, R.D. Noble, Room-Temperature Ionic Liquid-Amine Solutions: Tunable Solvents for Efficient and Reversible Capture of CO2, Ind. Eng. Chem. Res., 47 (2008) 84968498.

[24] M. Gonzalez-Miquel, J. Palomar, S. Omar, F. Rodriguez, CO2/N2 Selectivity Prediction in Supported Ionic Liquid Membranes (SILMs) by COSMO-RS, Ind. Eng. Chem. Res., 50 (2011) 57395748.

[25] P.T. Nguyen, B.A. Voss, E.F. Wiesenauer, D.L. Gin, R.D. Noble, Physically Gelled RoomTemperature Ionic Liquid-Based Composite Membranes for CO2/N2 Separation: Effect of Composition and Thickness on Membrane Properties and Performance, Ind. Eng. Chem. Res., 52 (2012) 8812-8821.

[26] T.K. Carlisle, E.F. Wiesenauer, G.D. Nicodemus, D.L. Gin, R.D. Noble, Ideal CO2/Light Gas Separation Performance of Poly(vinylimidazolium) Membranes and Poly(vinylimidazolium)-Ionic Liquid Composite Films, Ind. Eng. Chem. Res., 52 (2012) 1023-1032.

[27] J. Chau, G. Obuskovic, X. Jie, T. Mulukutla, K.K. Sirkar, Solubilities of CO2 and Helium in an Ionic Liquid Containing Poly(amidoamine) Dendrimer Gen 0, Ind. Eng. Chem. Res., 52 (2013) 10484-10494. [28] J. Zhang, C. Jia, H. Dong, J. Wang, X. Zhang, S. Zhang, A Novel Dual Amino-Functionalized Cation-Tethered Ionic Liquid for CO2 Capture, Ind. Eng. Chem. Res., 52 (2013) 5835-5841.

[29] J.R. Switzer, A.L. Ethier, K.M. Flack, E.J. Biddinger, L. Gelbaum, P. Pollet, C.A. Eckert, C.L. Liotta, Reversible Ionic Liquid Stabilized Carbamic Acids: A Pathway Toward Enhanced CO2 Capture, Industrial \& Engineering Chemistry Research, (2013).

[30] J.R. Switzer, A.L. Ethier, K.M. Flack, E.J. Biddinger, L. Gelbaum, P. Pollet, C.A. Eckert, C.L. Liotta, Reversible Ionic Liquid Stabilized Carbamic Acids: A Pathway Toward Enhanced CO2 Capture, Ind. Eng. Chem. Res., 52 (2013) 13159-13163.

[31] D. Zhao, M. Wu, Y. Kou, E. Min, Ionic liquids: applications in catalysis, Catal. Today, 74 (2002) 157-189.

[32] P. Wasserscheid, M. Haumann, Catalyst Recycling Using Ionic Liquids, in: D. Cole-Hamilton, R. Tooze (Eds.) Catalyst Separation, Recovery and Recycling, Springer Netherlands, 2006, pp. 183-213. [33] H. Olivier-Bourbigou, L. Magna, D. Morvan, Ionic liquids and catalysis: Recent progress from knowledge to applications, Applied Catalysis A: General, 373 (2010) 1-56.

[34] J. Stoimenovski, D. MacFarlane, K. Bica, R. Rogers, Crystalline vs. Ionic Liquid Salt Forms of Active Pharmaceutical Ingredients: A Position Paper, Pharm. Res., 27 (2010) 521-526.

[35] J.P. Gutiérrez, G.W. Meindersma, A.B. de Haan, COSMO-RS-Based Ionic-Liquid Selection for Extractive Distillation Processes, Ind. Eng. Chem. Res., 51 (2012) 11518-11529.

[36] M. Liu, S. Jia, Y. Gong, C. Song, X. Guo, Effective Hydrolysis of Cellulose into Glucose over Sulfonated Sugar-Derived Carbon in an Ionic Liquid, Ind. Eng. Chem. Res., 52 (2013) 8167-8173. [37] X. Liang, Novel Efficient Procedure for Biodiesel Synthesis from Waste Oils Using Solid Acidic Ionic Liquid Polymer As the Catalyst, Ind. Eng. Chem. Res., 52 (2013) 6894-6900.

[38] M.H. Ghatee, F. Moosavi, A.R. Zolghadr, R. Jahromi, Critical-Point Temperature of Ionic Liquids from Surface Tension at Liquid-Vapor Equilibrium and the Correlation with the Interaction Energy, Ind. Eng. Chem. Res., 49 (2010) 12696-12701.

[39] J.O. Valderrama, P.A. Robles, Critical Properties, Normal Boiling Temperatures, and Acentric Factors of Fifty Ionic Liquids, Ind. Eng. Chem. Res., 46 (2007) 1338-1344.

[40] L.P.N. Rebelo, J.N. Canongia Lopes, J.M.S.S. Esperança, E. Filipe, On the Critical Temperature, Normal Boiling Point, and Vapor Pressure of Ionic Liquids, J. Phys. Chem. B, 109 (2005) 6040-6043. [41] J.L. Shereshefsky, Surface Tension of Saturated Vapors and the Equation of Eötvös, The Journal of Physical Chemistry, 35 (1930) 1712-1720.

[42] E.A. Guggenheim, The Principle of Corresponding States, The Journal of Chemical Physics, 13 (1945) 253-261. 
[43] U. Domańska, K. Skiba, M. Zawadzki, K. Paduszyński, M. Królikowski, Synthesis, physical, and thermodynamic properties of 1-alkyl-cyanopyridinium bis \{(trifluoromethyl)sulfonyl $\}$ imide ionic liquids, JChTh, 56 (2013) 153-161.

[44] U. Domańska, Z. Żołek-Tryznowska, Effect of Temperature and Composition on the Surface Tension and Thermodynamic Properties of Binary Mixtures of Boltorn U3000 with Alcohols and Ether, J. Solution Chem., 39 (2010) 864-876.

[45] A. Shariati, S.-S. Ashrafmansouri, M. Osbuei, B. Hooshdaran, Critical properties and acentric factors of ionic liquids, Korean J. Chem. Eng., 30 (2013) 187-193.

[46] U. Domańska, M. Zawadzki, A. Lewandrowska, Effect of temperature and composition on the density, viscosity, surface tension, and thermodynamic properties of binary mixtures of $\mathrm{N}$ octylisoquinolinium bis $\{$ (trifluoromethyl)sulfonyl $\}$ imide with alcohols, JChTh, 48 (2012) 101-111. [47] M. Zawadzki, L. Niedzicki, W. Wieczorek, U. Domańska, Estimation of extraction properties of new imidazolide anion based ionic liquids on the basis of activity coefficient at infinite dilution measurements, Sep. Purif. Technol., 118 (2013) 242-254.

[48] J.O. Valderrama, B.F. Abu-Sharkh, Generalized rackett-type correlations to predict the density of saturated liquids and petroleum fractions, Fluid Phase Equilib., 51 (1989) 87-100.

[49] J.O. Valderrama, L.A. Forero, R.E. Rojas, Critical Properties and Normal Boiling Temperature of Ionic Liquids. Update and a New Consistency Test, Ind. Eng. Chem. Res., 51 (2012) 7838-7844.

[50] K.-J. Wu, Q.-L. Chen, C.-H. He, Speed of sound of ionic liquids: Database, estimation, and its application for thermal conductivity prediction, AlChE J., 60 (2014) 1120-1131.

[51] O.M. Basha, Y.J. Heintz, M.J. Keller, D.R. Luebke, K.P. Resnik, B.I. Morsi, Development of a Conceptual Process for Selective Capture of CO2 from Fuel Gas Streams Using Two TEGO Ionic Liquids as Physical Solvents, Ind. Eng. Chem. Res., 53 (2014) 3184-3195.

[52] M. Zoubeik, A. Henni, Experimental and thermodynamic study of $\mathrm{CO} 2$ solubility in promising [TF2N and DCN] ionic liquids, Fluid Phase Equilib., 376 (2014) 22-30.

[53] A. Tagiuri, K.Z. Sumon, A. Henni, Solubility of carbon dioxide in three [Tf2N] ionic liquids, Fluid Phase Equilib., 380 (2014) 39-47.

[54] M.A. Ahmadi, R. Haghbakhsh, R. Soleimani, M.B. Bajestani, Estimation of H2S solubility in ionic liquids using a rigorous method, The Journal of Supercritical Fluids, 92 (2014) 60-69.

[55] A. Shafiei, M.A. Ahmadi, S.H. Zaheri, A. Baghban, A. Amirfakhrian, R. Soleimani, Estimating hydrogen sulfide solubility in ionic liquids using a machine learning approach, The Journal of Supercritical Fluids.

[56] S. Hong, Y. Park, D. Pore, Experimental determination and prediction of phase behavior for 1-butyl3-methylimidazolium nonafluorobutyl sulfonate and carbon dioxide, Korean J. Chem. Eng., 31 (2014) 1656-1660.

[57] A. Eslamimanesh, F. Gharagheizi, A.H. Mohammadi, D. Richon, Artificial Neural Network modeling of solubility of supercritical carbon dioxide in 24 commonly used ionic liquids, Chem. Eng. Sci., 66 (2011) 3039-3044.

[58] M. Frenkel, R.D. Chirico, V. Diky, C.D. Muzny, A.F. Kazakov, J.W. Magee, I.M. Abdulagatov, K. Kroenlein, C.A. Diaz-Tovar, J.W. Kang, R. Gani, ThermoData Engine, NIST Standard Reference Database \#103b (Pure Compounds, Binary Mixtures, and Chemical Reactions), version 7.0, in, National Institute of Standards and Technology, Gaithersburg, MD 20899, USA, http://www.nist.gov/srd/nist103b.cfm, 2011.

[59] H. Jiang, Y. Zhao, J. Wang, F. Zhao, R. Liu, Y. Hu, Density and surface tension of pure ionic liquid 1-butyl-3-methyl-imidazolium 1-lactate and its binary mixture with alcohol and water, JChTh, 64 (2013) $1-13$.

[60] M.H. Ghatee, M. Bahrami, N. Khanjari, Measurement and study of density, surface tension, and viscosity of quaternary ammonium-based ionic liquids ([N222(n)]Tf2N), JChTh, 65 (2013) 42-52. [61] Y. Wei, Y. Jin, Z.-J. Wu, Y. Yang, Q.-G. Zhang, Z.-H. Kang, Synthesis and Physicochemical Properties of Amino Acid Ionic Liquid 1-Butyl-3-methylimidazolium Aspartate and Binary Mixture with Methanol, J. Chem. Eng. Data, 58 (2013) 349-356. 
[62] H.F.D. Almeida, J.A. Lopes-da-Silva, M.G. Freire, J.A.P. Coutinho, Surface tension and refractive index of pure and water-saturated tetradecyltrihexylphosphonium-based ionic liquids, JChTh, 57 (2013) 372-379.

[63] A. Xu, Y. Zhang, Z. Li, J. Wang, Effect of Substituent Groups in Anions on Some Physicochemical Properties of 1-Butyl-3-methylimidazolium Carboxylate Ionic Liquids, J. Chem. Eng. Data, 58 (2013) 2496-2501.

[64] M.H. Keshavarz, S. Moradi, B.E. Saatluo, H. Rahimi, A.R. Madram, A simple accurate model for prediction of deflagration temperature of energetic compounds, J. Therm. Anal. Calorim., 112 (2013) 1453-1463.

[65] S. Benessam, K. Khimeche, F. Djellouli, M. Benziane, A. Dahmani, Phase diagram of ibuprofen with fatty acids, J. Therm. Anal. Calorim., 112 (2013) 317-320.

[66] B. Marongiu, S. Porcedda, D. Falconieri, A. Piras, E. Matteoli, L. Lepori, Excess enthalpies of mixtures of mono-carboxylic acid with dibutylether: Comparison with DISQUAC predictions, J. Therm. Anal. Calorim., 108 (2012) 777-782.

[67] H. Piekarski, A. Pietrzak, Enthalpic interaction coefficients of NaI-Alkanediol pairs in methanol and in water, J. Therm. Anal. Calorim., 110 (2012) 917-922.

[68] M. Sattari, F. Gharagheizi, P. Ilani-Kashkouli, A. Mohammadi, D. Ramjugernath, Development of a group contribution method for the estimation of heat capacities of ionic liquids, J. Therm. Anal. Calorim., 115 (2014) 1863-1882.

[69] M. Sattari, F. Gharagheizi, P. Ilani-Kashkouli, A.H. Mohammadi, D. Ramjugernath, Determination of the speed of sound in ionic liquids using a least squares support vector machine group contribution method, Fluid Phase Equilib., 367 (2014) 188-193.

[70] M. Sattari, A. Kamari, A.H. Mohammadi, D. Ramjugernath, A group contribution method for estimating the refractive indices of ionic liquids, J. Mol. Liq., 200, Part B (2014) 410-415.

[71] M. Sattari, F. Gharagheizi, Prediction of molecular diffusivity of pure components into air: a QSPR approach, Chemosphere, 72 (2008) 1298-1302.

[72] M. Sattari, F. Gharagheizi, P. Ilani-Kashkouli, A.H. Mohammadi, D. Ramjugernath, A chemical structure based model for the determination of speed of sound in ionic liquids, J. Mol. Liq., 196 (2014) 7 13.

[73] M. Sattari, A. Kamari, A.H. Mohammadi, D. Ramjugernath, Prediction of refractive indices of ionic liquids - A quantitative structure-property relationship based model, J. Taiwan. Inst. Chem. Eng., 52 (2015) 165-180.

[74] M. Sattari, F. Gharagheizi, P. Ilani-Kashkouli, A.H. Mohammadi, D. Ramjugernath, Estimation of the Heat Capacity of Ionic Liquids: A Quantitative Structure-Property RelationshipApproach, Ind. Eng. Chem. Res., 52 (2013) 13217-13221.

[75] Talete srl, DRAGON for Windows (Software for Molecular Descriptor Calculations) Version 5.5, 2007., in.

[76] D.H. Zaitsau, G.J. Kabo, A.A. Strechan, Y.U. Paulechka, A. Tschersich, S.P. Verevkin, A. Heintz, Experimental Vapor Pressures of 1-Alkyl-3-methylimidazolium Bis(trifluoromethylsulfonyl)imides and a Correlation Scheme for Estimation of Vaporization Enthalpies of Ionic Liquids, The Journal of Physical Chemistry A, 110 (2006) 7303-7306.

[77] J.O. Valderrama, W.W. Sanga, J.A. Lazzús, Critical properties, normal boiling temperature, and acentric factor of another 200 ionic liquids, Ind. Eng. Chem. Res., 47 (2008) 1318-1330. 
Figure 1: The number of ionic liquids in different families used for modeling the critical temperature. Figure 2: A comparison between the $T_{c}$ estimated by Guggenheim equation and other methods.

Figure 3: Estimated $T_{c}$ of 1-ethyl-3-methylimidazolium ILs by different models.

Figure 4: Estimated $T_{c}$ of 1-butyl-3-methylimidazolium ILs by different models.

Figure 5: $T_{c}$ of 1-ethyl-3-methylimidazolium ionic liquids with 45 different anions calculated by the QSPR and Valderrama et al. models. 
Table 1: Statistical parameters of GC and QSPR models

Table 2: Comparison of estimated $T_{c}$ of ionic liquids by different methods. 


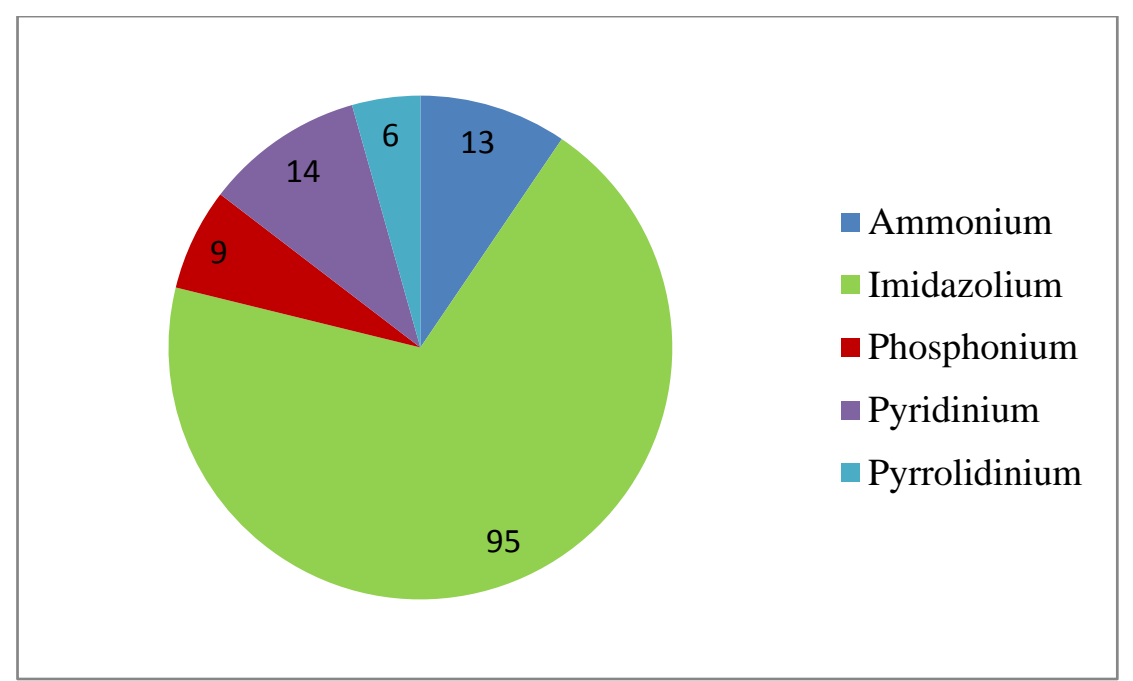

Figure 1: The number of ionic liquids in different families used for modeling the critical temperature. 


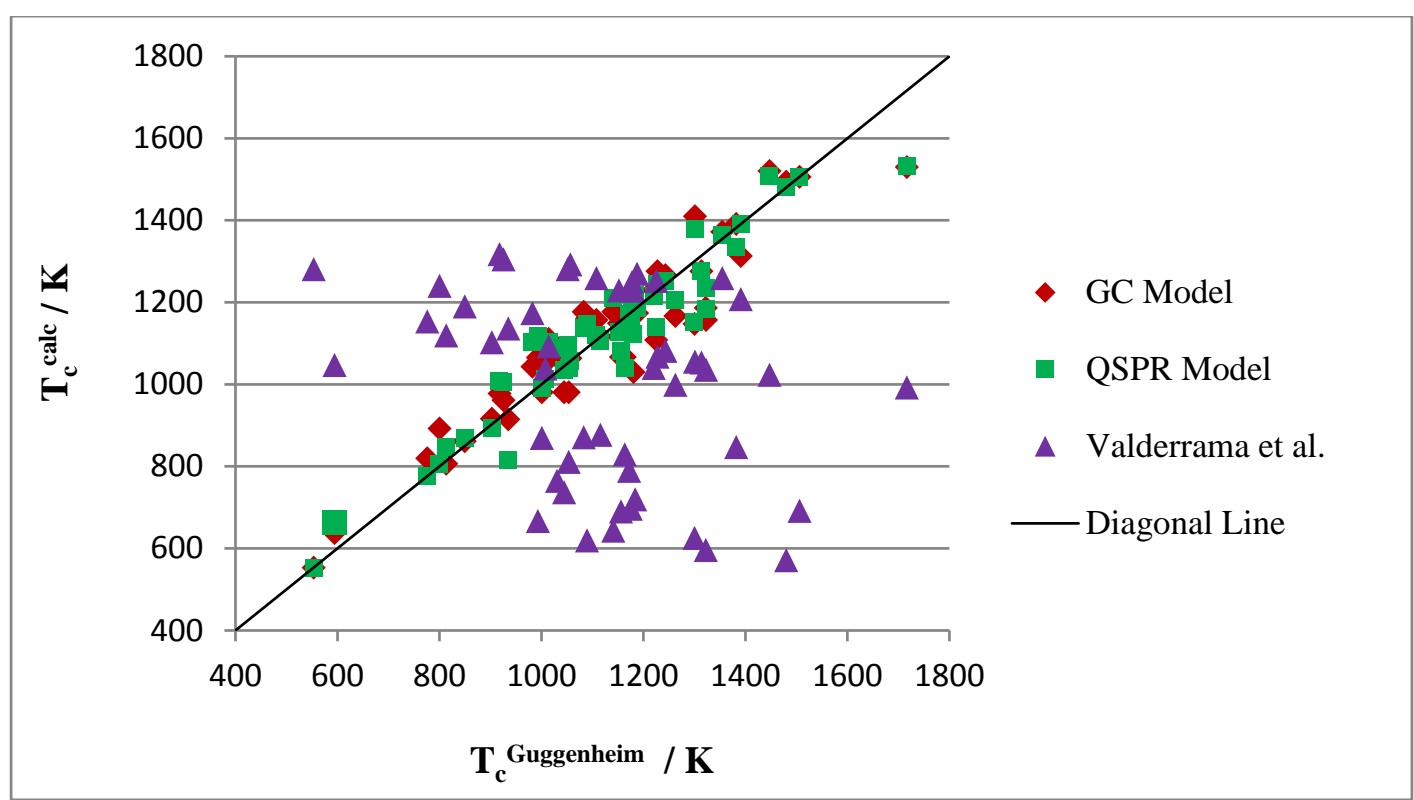

Figure 2: A comparison between the $T_{c}$ estimated by Guggenheim equation and other methods. 


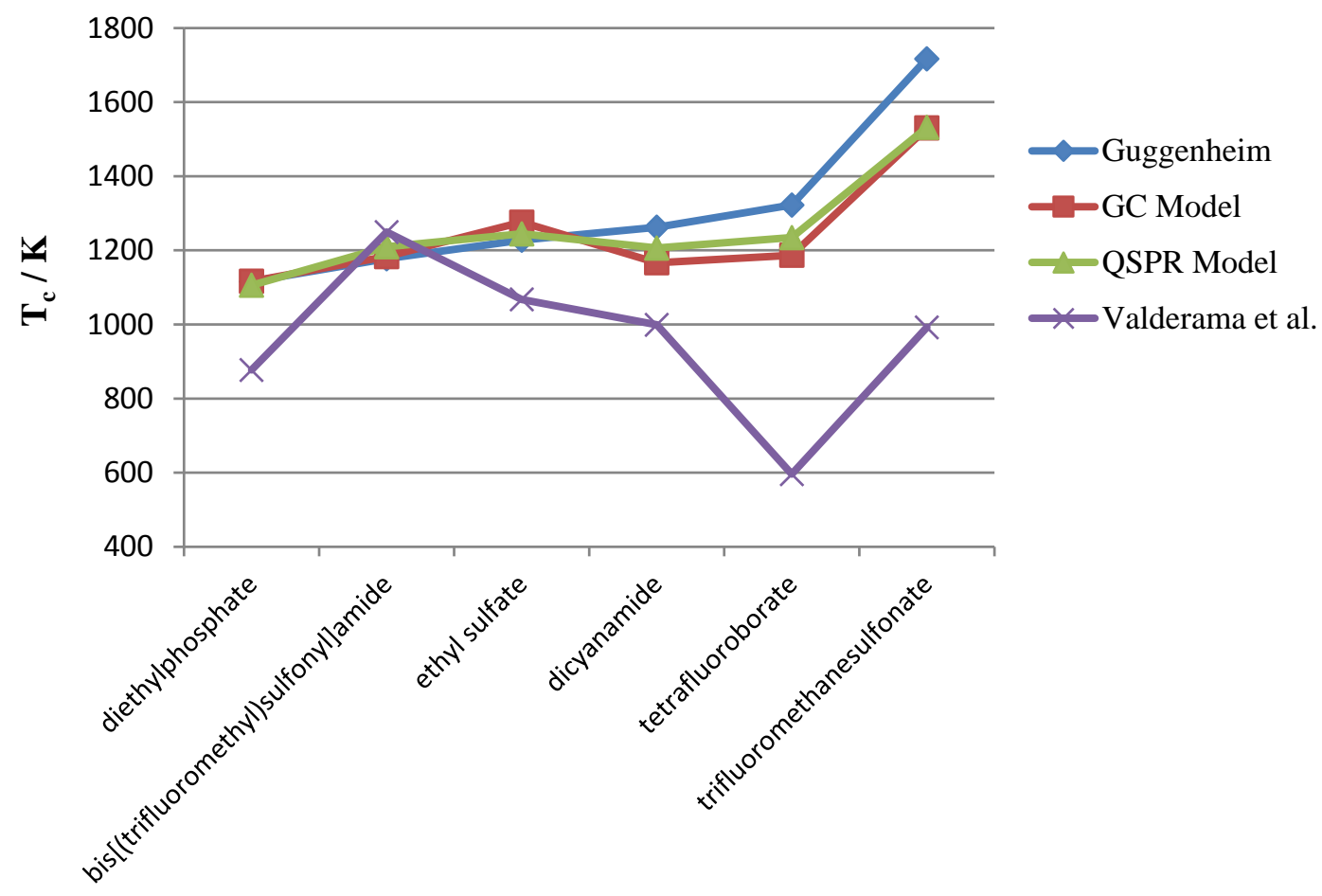

Figure 3: Estimated $T_{c}$ of 1-ethyl-3-methylimidazolium ILs by different models. 


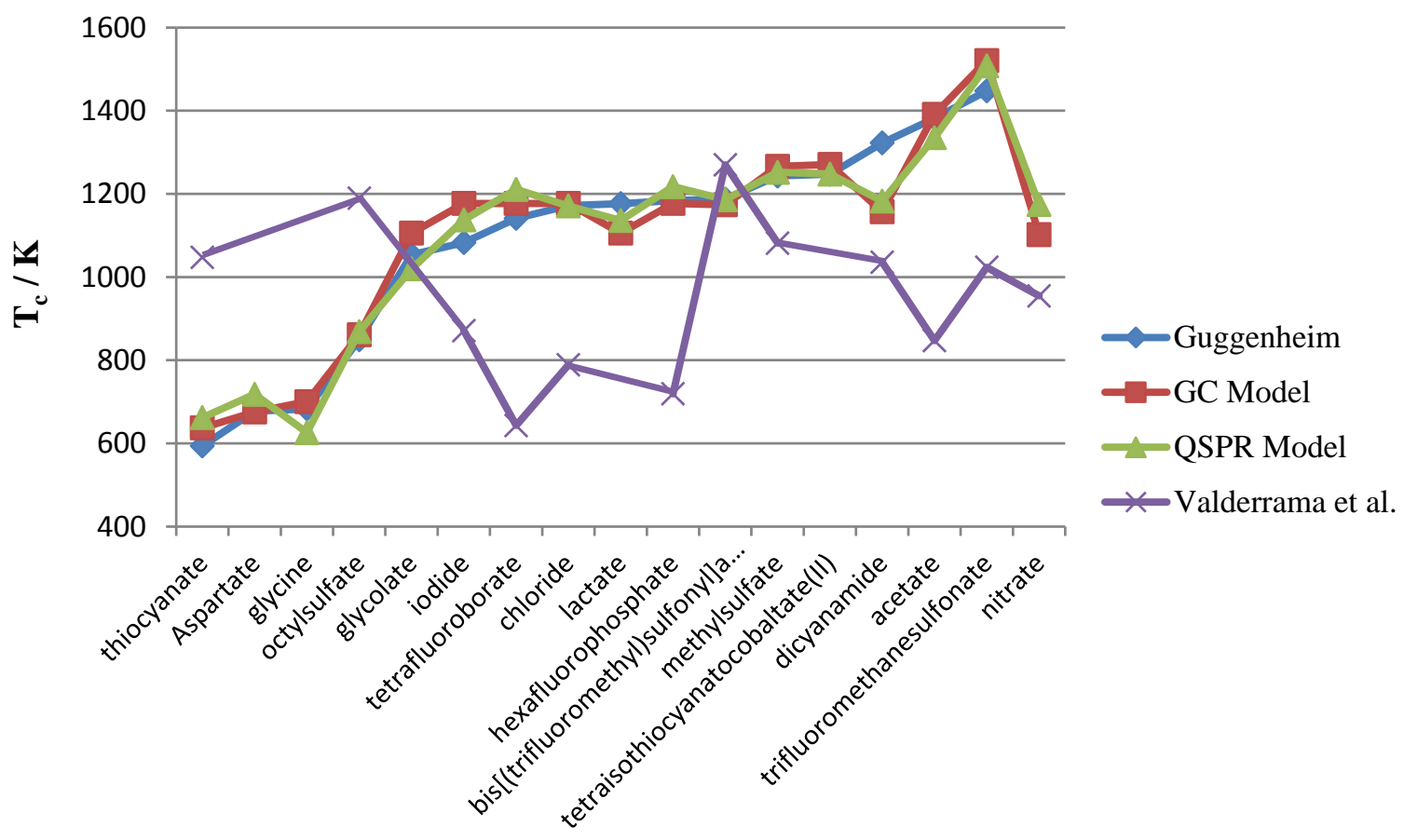

Figure 4: Estimated $T_{c}$ of 1-butyl-3-methylimidazolium ILs by different models. 


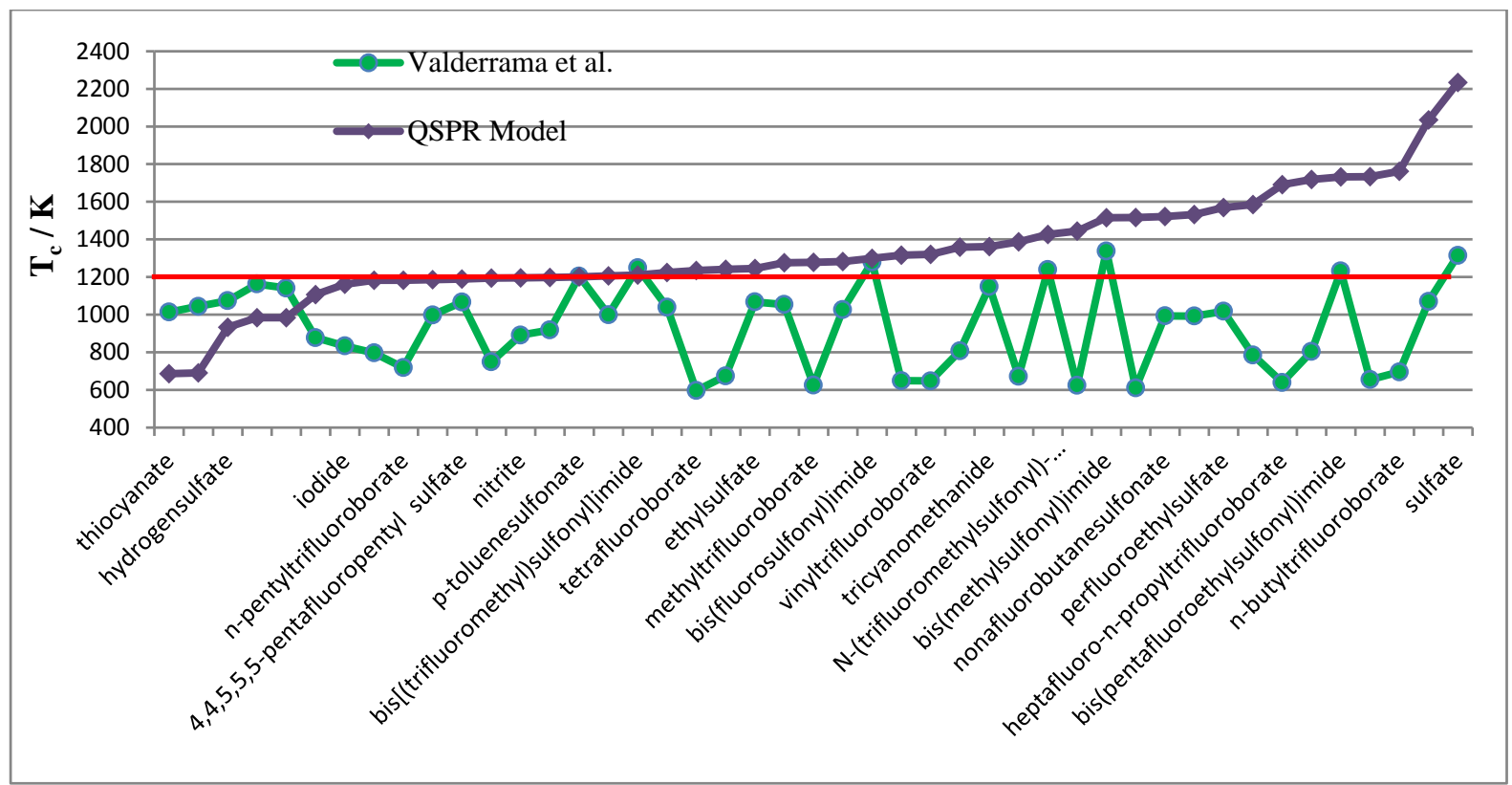

Figure 5: $T_{c}$ of 1-ethyl-3-methylimidazolium ionic liquids with 45 different anions calculated by the QSPR and Valderrama et al. models. 


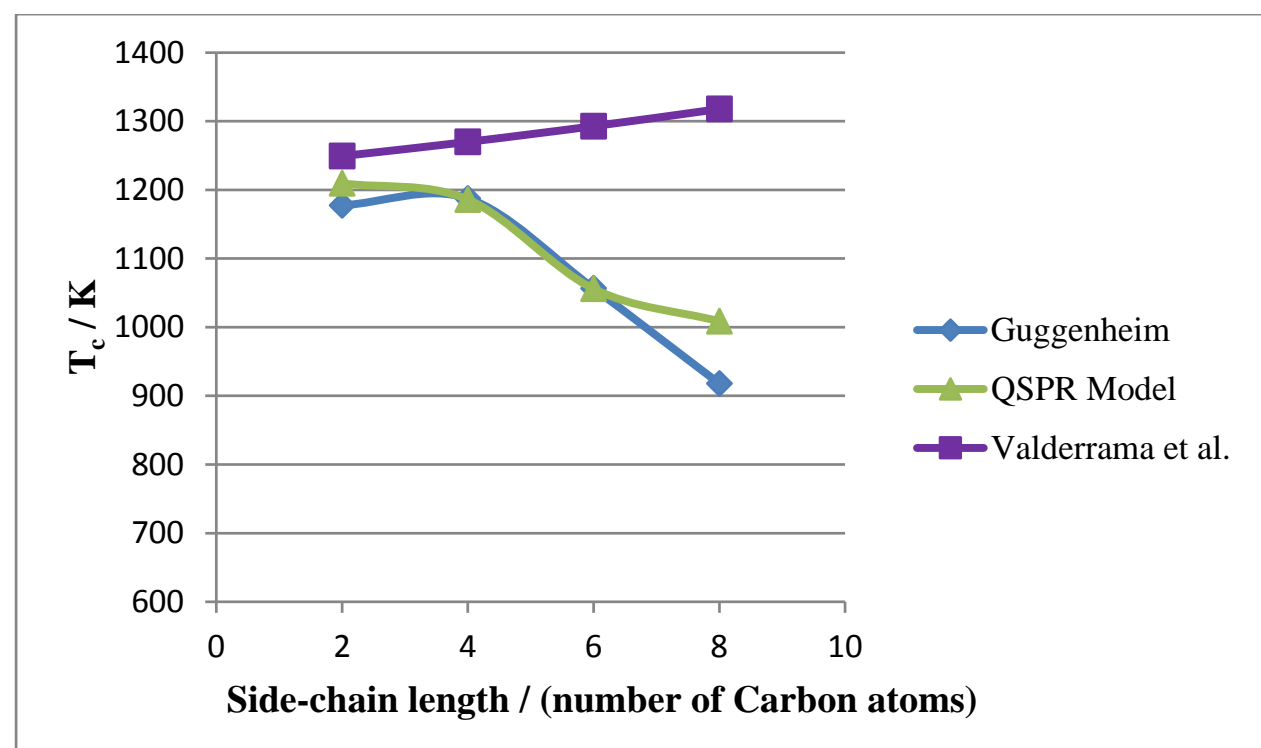

Figure 6: Estimated $T_{c}$ of 1-alkyl-3-methylimidazolium bis[(trifluoromethyl)sulfonyl]imide ILs by different models. 


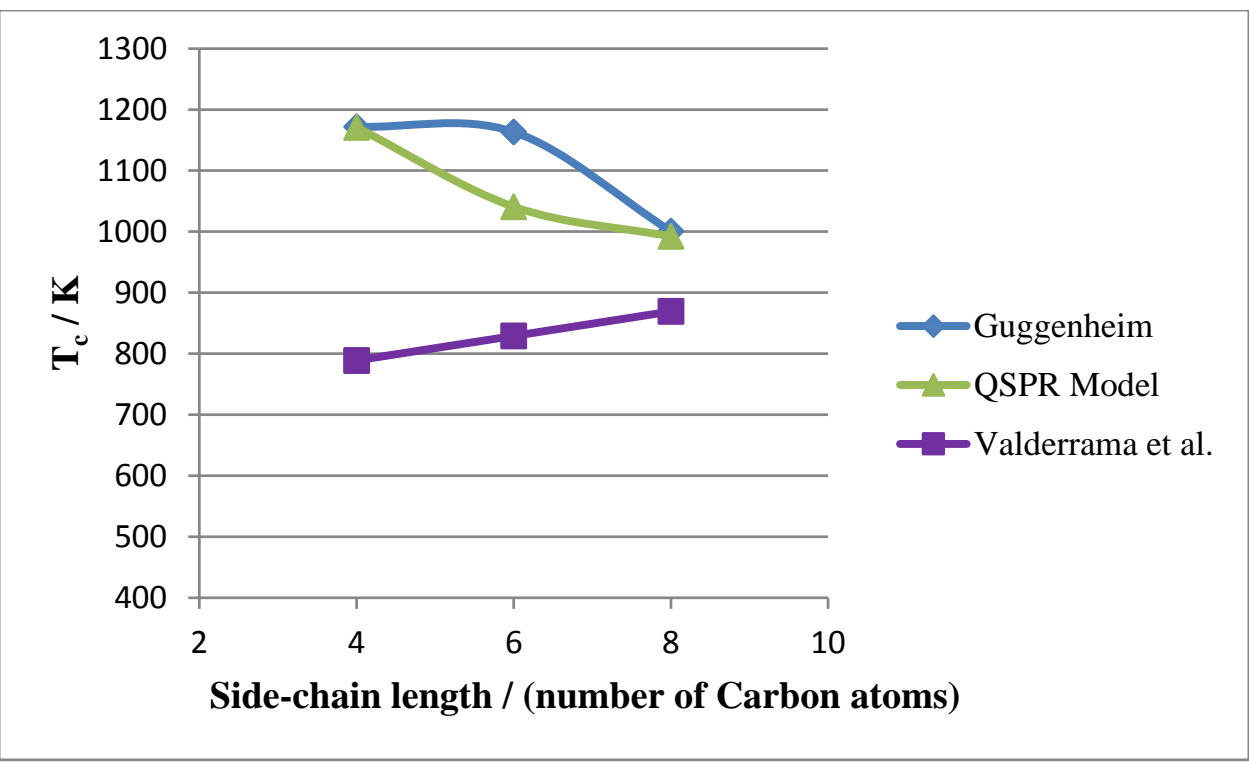

Figure 7: Estimated $T_{c}$ of 1-alkyl-3-methylimidazolium Chloride ILs by different models. 
Table 1: Statistical parameters of GC and QSPR models

\begin{tabular}{lrr}
\hline Statistical Parameter & GC Model & QSPR Model \\
\hline \multicolumn{1}{c}{ training set } & & \\
$\mathrm{R}^{2 \mathrm{a}}$ & 0.925 & 0.934 \\
Average absolute relative deviation $^{\mathrm{b}}$ & 5.19 & 4.95 \\
Standard deviation error $^{\mathrm{c}}$ & 69.57 & 65.32 \\
Root mean square error $^{\mathrm{d}}$ & 69.60 & 65.34 \\
$\mathrm{~N}$ & 82 & 82
\end{tabular}

test set

$\begin{array}{lll}\mathrm{R}^{2} & 0.911 & 0.941\end{array}$

$\begin{array}{lrr}\text { Average absolute relative deviation } & 5.12 & 3.84\end{array}$

$\begin{array}{lll}\text { Standard deviation error } & 77.46 & 64.58\end{array}$

$\begin{array}{lll}\text { Root mean square error } & 77.72 & 64.65\end{array}$

$\mathrm{N}$

$24 \quad 24$

\section{total}

$\begin{array}{lrr}\mathrm{R}^{2} & 0.921 & 0.935\end{array}$

$\begin{array}{lll}\text { Average absolute relative deviation } & 5.17 & 4.70\end{array}$

$\begin{array}{lll}\text { Standard deviation error } & 71.52 & 65.18\end{array}$

$\begin{array}{lll}\text { Root mean square error } & 71.52 & 65.18\end{array}$

\begin{tabular}{lll}
$\mathrm{N}$ & 106 & 106 \\
\hline
\end{tabular}

${ }^{\mathrm{a}} R^{2}=1-\frac{\sum_{i=1}^{N}\left[y(i)_{c a l c}-y(i)_{e x p}\right]^{2}}{\sum_{i=1}^{N}\left[y(i)_{c a l c}-\bar{y}_{e x p}\right]^{2}}$

${ }^{\mathrm{b}} A A R D \%=\frac{100}{N} \sum_{i=1}^{N}\left|\frac{y(i)_{\text {calc }}-y(i)_{\exp }}{y(i)_{\exp }}\right|$

${ }^{\mathrm{c}} S D E C=\sqrt{\frac{1}{N} \sum_{i=1}^{N}[e(i)-\bar{e}]^{2}},\left(e=y_{\text {calc }}-y_{\text {exp }}\right)$

${ }^{\mathrm{d}} R M S E=\sqrt{\frac{1}{N} \sum_{i=1}^{N}\left[y(i)_{c a l c}-y(i)_{\text {exp }}\right]^{2}}$ 
Table 2: Comparison of estimated $T_{c}$ of ionic liquids by different methods.

\begin{tabular}{|c|c|c|c|c|c|}
\hline \multirow[b]{2}{*}{ No. } & \multirow[b]{2}{*}{ Name } & \multicolumn{4}{|c|}{$\mathrm{T}_{\mathrm{c}}$} \\
\hline & & $\begin{array}{l}\text { Guggenheim } \\
\text { Equation }\end{array}$ & $\begin{array}{c}\text { GC } \\
\text { Model }\end{array}$ & $\begin{array}{l}\text { QSPR } \\
\text { Model }\end{array}$ & $\begin{array}{l}\text { Valderrama } \\
\text { et al. [49] }\end{array}$ \\
\hline 1 & 1-(2-aminoethyl)-3-methylimidazolium tetrafluoroborate & 1086.1 & 1119.0 & 1093.0 & n.a. \\
\hline 2 & 1-(2-hydroxyethyl)-3-methylimidazolium tetrafluoroborate & 1506.2 & 1506.2 & 1506.2 & 691.9 \\
\hline 3 & 1-(3-aminopropyl)-3-methylimidazolium tetrafluoroborate & 1115.7 & 1023.1 & 1134.2 & n.a. \\
\hline 4 & 1,2-dimethyl-3-propylimidazolium bis[(trifluoromethyl)sulfonyl]amide & n.a. & 536.5 & 543.8 & 1269.7 \\
\hline 5 & 1,3-diethylimidazolium bis[(trifluoromethyl)sulfonyl]amide & 1354.6 & 1372.0 & 1363.1 & 1259.3 \\
\hline 6 & 1,3-dimethylimidazolium dimethylphosphate & 636.5 & 635.8 & 646.2 & n.a. \\
\hline 7 & 1,3-dimethylimidazolium methyl sulfate & 1220.3 & 1230.1 & 1215.2 & 1040 \\
\hline 8 & 1-butyl-1-methylpyrrolidinium bis[(trifluoromethyl)sulfonyl]amide & 1014.3 & 1110.9 & 1103.6 & 1093.1 \\
\hline 9 & 1-butyl-1-methylpyrrolidinium dicyanamide & 1015.2 & 1094.2 & 1100.2 & n.a. \\
\hline 10 & 1-butyl-1-methylpyrrolidinium thiocyanate & 736.0 & 574.4 & 579.5 & n.a. \\
\hline 11 & 1-butyl-1-methylpyrrolidinium trifluoroacetate & 1431.0 & 1401.0 & 1479.0 & n.a. \\
\hline 12 & 1-butyl-1-methylpyrrolidinium tris(pentafluoroethyl)trifluorophosphate & n.a. & 1058.0 & 1037.2 & n.a. \\
\hline 13 & 1-butyl-2,3-dimethylimidazolium bis(trifluoromethylsulfonyl)imide & 553.1 & 553.1 & 553.1 & 1281.1 \\
\hline 14 & 1-butyl-3-(6-hydroxyhexyl)-imidazolium chloride & 456.4 & 434.2 & 475.2 & n.a. \\
\hline 15 & 1-butyl-3-methylimidazolium acetate & 1381.8 & 1391.0 & 1335.1 & 847.3 \\
\hline 16 & 1-butyl-3-methylimidazolium Aspartate & 677.1 & 675.5 & 718.3 & n.a. \\
\hline 17 & 1-butyl-3-methylimidazolium bis[(trifluoromethyl)sulfonyl]amide & 1187.6 & 1173.7 & 1186.1 & 1269.9 \\
\hline 18 & 1-butyl-3-methylimidazolium chloride & 1171.8 & 1177.0 & 1171.0 & 789 \\
\hline 19 & 1-butyl-3-methylimidazolium dicyanamide & 1322.5 & 1157.0 & 1182.7 & 1035.8 \\
\hline 20 & 1-butyl-3-methylimidazolium glutamine & 471.3 & 462.1 & 466.8 & n.a. \\
\hline 21 & 1-butyl-3-methylimidazolium glycine & 683.1 & 700.5 & 626.0 & n.a. \\
\hline 22 & 1-butyl-3-methylimidazolium glycolate & 1053.6 & 1105.7 & 1019.8 & n.a. \\
\hline 23 & 1-butyl-3-methylimidazolium hexafluorophosphate & 1183.9 & 1177.0 & 1217.4 & 719.4 \\
\hline 24 & 1-butyl-3-methylimidazolium iodide & 1082.9 & 1177.0 & 1137.4 & 871.2 \\
\hline 25 & 1-butyl-3-methylimidazolium lactate & 1176.5 & 1105.7 & 1136.0 & n.a. \\
\hline 26 & 1-butyl-3-methyl-imidazolium L-lactate & 1276.3 & 1105.7 & 1136.0 & n.a. \\
\hline 27 & 1-butyl-3-methylimidazolium methylsulfate & 1242.9 & 1266.2 & 1252.0 & 1081.6 \\
\hline 28 & 1-butyl-3-methylimidazolium nitrate & n.a. & 1102.1 & 1174.2 & 954.8 \\
\hline 29 & 1-butyl-3-methylimidazolium octylsulfate & 849.3 & 861.2 & 868.8 & 1189.8 \\
\hline 30 & 1-butyl-3-methylimidazolium tetrafluoroborate & 1141.1 & 1177.0 & 1210.8 & 643.2 \\
\hline 31 & 1-butyl-3-methylimidazolium tetraisothiocyanatocobaltate(II) & 1247.2 & 1270.8 & 1247.6 & n.a. \\
\hline 32 & 1-butyl-3-methylimidazolium thiocyanate & 594.0 & 637.3 & 662.0 & 1047.4 \\
\hline 33 & 1-butyl-3-methylimidazolium trifluoromethanesulfonate & 1447.5 & 1520.5 & 1508.1 & 1023.5 \\
\hline 34 & 1-butyl-3-methylpyridinium bis[(trifluoromethyl)sulfonyl]amide & 800.1 & 892.3 & 805.5 & 1240.5 \\
\hline 35 & 1-butyl-4-methylpyridinium thiocyanate & 513.8 & 607.9 & 602.0 & n.a. \\
\hline 36 & 1-butylpyridinium bis[(trifluoromethyl)sulfonyl]amide & 1151.8 & 1148.9 & 1127.2 & 1229.1 \\
\hline 37 & 1-butylpyridinium heptachlorodialuminate & 1089.1 & 1089.1 & 1085.9 & n.a. \\
\hline 38 & 1-butylpyridinium nitrate & 1089.9 & 1077.2 & 1115.3 & n.a. \\
\hline 39 & 1-decyl-3-methylimidazolium bis(trifluoromethylsulfonyl)amide & 875.8 & 923.3 & 802.9 & n.a. \\
\hline
\end{tabular}


40 1-dodecyl-3-methylimidazolium hexafluorophosphate

41 1-dodecyl-3-methylimidazolium tetrafluoroborate

42 1-ethyl-3-(6-hydroxyhexyl)-imidazolium chloride

43 1-ethyl-3-methylimazolium methylsulfate

44 1-ethyl-3-methylimidazolium 1,1,2,2-tetrafluoroethanesulfonate

45 1-ethyl-3-methylimidazolium acetate

46 1-ethyl-3-methylimidazolium bis[(pentafluoroethyl)sulfonyl]amide

47 1-ethyl-3-methylimidazolium bis[(trifluoromethyl)sulfonyl]amide

48 1-ethyl-3-methylimidazolium dicyanamide

49 1-ethyl-3-methylimidazolium diethylphosphate

50 1-ethyl-3-methylimidazolium ethyl sulfate

51 1-ethyl-3-methylimidazolium hexylsulfate

52 1-ethyl-3-methylimidazolium L-lactate

53 1-ethyl-3-methylimidazolium octyl sulfate

54 1-ethyl-3-methylimidazolium tetrachloroindate

55 1-ethyl-3-methylimidazolium tetracyanoborate

56 1-ethyl-3-methylimidazolium tetrafluoroborate

57 1-ethyl-3-methylimidazolium trifluoromethanesulfonate

58 1-ethyl-3-methylimidazolium tris(pentafluoroethyl)trifluorophosphate

59 1-ethylpyridinium bis[(trifluoromethyl)sulfonyl]amide

60 1-heptyl-3-methylimidazolium bis(trifluoromethylsulfonyl)amide

61 1-hexyl-3-methylimidazolium bis[(trifluoromethyl)sulfonyl]amide

62 1-hexyl-3-methylimidazolium chloride

63 1-hexyl-3-methylimidazolium hexafluorophosphate

64 1-hexyl-3-methylimidazolium iodide

65 1-hexyl-3-methylimidazolium nitrate

66 1-hexyl-3-methylimidazolium tetrafluoroborate

67 1-hexyl-3-methylimidazolium trifluoromethanesulfonate

68 1-hexyl-3-methylimidazolium tris(pentafluoroethyl)trifluorophosphate

69 1-hexylpyridinium bis(trifluromethylsulfonyl)imide

70 1-isobutenyl-3-methylimidazolium tetrafluoroborate

71 1-methyl-1-propylpyrrolidinium bis[(trifluoromethyl)sulfonyl]amide

72 1-methyl-3-hexylimidazolium chloroindium

73 1-octyl-3-methylimidazolium chloride

74 1-methyl-3-pentylimidazolium 1,1,2,2,2-pentafluoro-N-[(1,1,2,2,2pentafluoroethyl)sulfonyl]ethanesulfonamide

75 1-methyl-3-pentylimidazolium aluminum tetrachloride

76 1-methyl-3-pentylimidazolium gallium tetrachloride

77 1-methyl-3-pentylimidazolium nitrate

78 1-methyl-3-pentylimidazolium tetrachloroindate

79 1-methyl-3-pentylimidazolium tetrafluoroborate

80 1-methyl-3-propylimidazolium bis(pentafluoroethylsulfonyl)imide

81 1-methyl-3-propylimidazolium bis[(trifluoromethyl)sulfonyl]amide

\begin{tabular}{|c|c|c|c|}
\hline n.a. & 901.2 & 829.1 & 857.6 \\
\hline n.a. & 901.2 & 822.5 & 784.6 \\
\hline 505.0 & 527.2 & 460.9 & n.a. \\
\hline 1313.5 & 1275.9 & 1275.6 & 1053.6 \\
\hline 1180.0 & 1184.6 & 1186.3 & n.a. \\
\hline n.a. & 1400.7 & 1358.7 & 807.1 \\
\hline n.a. & 492.3 & 1732.5 & 1231.4 \\
\hline 1177.5 & 1183.4 & 1209.7 & 1249.3 \\
\hline 1262.5 & 1166.7 & 1206.3 & 999 \\
\hline 1115.7 & 1116.4 & 1106.0 & 877.2 \\
\hline 1227.6 & 1275.9 & 1244.7 & 1067.5 \\
\hline n.a. & 870.9 & 1025.5 & n.a. \\
\hline 926.0 & 1115.4 & 1159.6 & n.a. \\
\hline n.a. & 870.9 & 892.4 & n.a. \\
\hline 1244.7 & 1314.1 & 1304.0 & n.a. \\
\hline 620.4 & 646.9 & 620.4 & n.a. \\
\hline 1322.2 & 1186.7 & 1234.4 & 596.2 \\
\hline 1716.8 & 1530.2 & 1531.7 & 992.3 \\
\hline 1057.3 & 1130.5 & 1143.3 & n.a. \\
\hline 1391.1 & 1312.8 & 1390.7 & 1207.9 \\
\hline 925.4 & 961.2 & 1006.4 & 1305 \\
\hline 1056.7 & 1063.5 & 1056.0 & 1292.8 \\
\hline 1163.2 & 1066.8 & 1040.8 & 829.2 \\
\hline 1030.4 & 1066.8 & 1087.3 & 764.9 \\
\hline 1012.4 & 1066.8 & 1007.3 & n.a. \\
\hline n.a. & 991.9 & 1044.1 & 991.8 \\
\hline 1155.8 & 1066.8 & 1080.6 & 690 \\
\hline 1301.1 & 1410.2 & 1378.0 & 1055.6 \\
\hline 950.0 & 1010.6 & 989.6 & n.a. \\
\hline 1224.9 & 1108.2 & 1140.9 & 1252.3 \\
\hline n.a. & 561.5 & 1133.3 & n.a. \\
\hline 1069.2 & 1107.1 & 1016.7 & n.a. \\
\hline 1172.9 & 1194.1 & 1148.3 & n.a. \\
\hline 1000.8 & 980.9 & 992.1 & 869.4 \\
\hline n.a. & 371.4 & 1616.6 & n.a. \\
\hline 1213.8 & 1193.1 & 1184.2 & n.a. \\
\hline 1247.8 & 1193.1 & 1190.8 & n.a. \\
\hline n.a. & 990.8 & 1082.0 & n.a. \\
\hline 1208.3 & 1193.1 & 1188.2 & n.a. \\
\hline 993.1 & 1065.7 & 1118.5 & 666.6 \\
\hline n.a. & 466.0 & 1642.8 & n.a. \\
\hline 1107.6 & 1157.1 & 1120.0 & 1259.3 \\
\hline
\end{tabular}


82 1-methyl-3-propylimidazolium hexafluorophosphate

83 1-methyl-3-propylimidazolium nitrate

84 1-octyl-3-methylimidazolium bis[(trifluoromethyl)sulfonyl]amide

85 1-octyl-3-methylimidazolium bromide

86 1-octyl-3-methylimidazolium hexafluorophosphate

87 1-octyl-3-methylimidazolium tetrafluoroborate

88 1-pentyl-3-methylimidazolium bis(trifluoromethylsulfonyl)amide

89 1-pentylpyridinium bis(trifluoromethylsulfonyl)imide

90 1-pentylpyridinium tetraoxorhenate

91 1-propyl-3-methylimidazolium glutamate

92 1-propyl-3-methylimidazolium tetrafluoroborate

93 1-propylpyridinium tetrafluoroborate

94 2-hydroxy ethylammonium formate

95 3-(6-hydroxyhexyl)-1-methylimidazolium chloride

96 3-(6-hydroxyhexyl)-imidazolium chloride

97 3,3'-(1,10-decanediyl)bis[1-methylimidazolium] 1,1,2,2,2-pentafluoro$\mathrm{N}$-[(1,1,2,2,2-pentafluoroethyl)sulfonyl]ethanesulfonamide

98 3,3'-(1,10-decanediyl)bis[1-methylimidazolium] bis(trifluoromethylsulfonyl)imide

99 3,3'-(1,10-decanediyl)bis[1-methylimidazolium] tetrafluoroborate

100 3,3'-(1,12-dodecanediyl)bis[1-methylimidazolium] 1,1,1-trifluoro-N[(trifluoromethyl)sulfonyl]methanesulfonamide

101 3,3'-(1,12-dodecanediyl)bis[1-methylimidazolium] 1,1,2,2,2pentafluoro-N-[(1,1,2,2,2-pentafluoroethyl)sulfonyl]ethanesulfonamide

102 3,3'-(1,12-dodecanediyl)bis[1-methylimidazolium] tetrafluoroborate

103 3,3'-(1,5-pentanediyl)bis[1-methylimidazolium] 1,1,1-trifluoro-N[(trifluoromethyl)sulfonyl]methanesulfonamide

104 3,3'-(1,5-pentanediyl)bis[1-methylimidazolium] 1,1,2,2,2-pentafluoro$\mathrm{N}$-[(1,1,2,2,2-pentafluoroethyl)sulfonyl]ethanesulfonamide

105 3,3'-(1,6-hexanediyl)bis[1-methylimidazolium] 1,1,1-trifluoro-N[(trifluoromethyl)sulfonyl]methanesulfonamide

106 3,3'-(1,6-hexanediyl)bis[1-methylimidazolium] 1,1,2,2,2-pentafluoro-N[(1,1,2,2,2-pentafluoroethyl)sulfonyl]ethanesulfonamide

107 3,3'-(1,8-octanediyl)bis[1-methylimidazolium] 1,1,1-trifluoro-N[(trifluoromethyl)sulfonyl]methanesulfonamide

108 3,3'-(1,9-nonanediyl)bis[1-methylimidazolium] 1,1,1-trifluoro-N[(trifluoromethyl)sulfonyl]methanesulfonamide

109 3,3'-(1,9-nonanediyl)bis[1-methylimidazolium] 1,1,2,2,2-pentafluoro-N$[(1,1,2,2,2$-pentafluoroethyl)sulfonyl]ethanesulfonamide

110 3,3'-(1,9-nonanediyl)bis[1-methylimidazolium] tetrafluoroborate

111 3-butyl-1-methylimidazolium benzoate

112 3-ethyl-1-methylimidazolium butyl sulfate

113 3-hexyl-1-methylimidazolium 1,1,2,2,2-pentafluoro-N-[(1,1,2,2,2pentafluoroethyl)sulfonyl] ethanesulfonamide

114 3-methyl-1-propylpyridinium bis(trifluoromethylsulfonyl)imide

\begin{tabular}{|c|c|c|c|}
\hline 1175.0 & 1160.4 & 1151.3 & 696.7 \\
\hline n.a. & 1085.5 & 1108.1 & n.a. \\
\hline 918.0 & 977.6 & 1008.7 & 1317.8 \\
\hline n.a. & 980.9 & 981.3 & 912.3 \\
\hline 1053.3 & 980.9 & 1040.0 & 810.8 \\
\hline 1044.6 & 980.9 & 1033.4 & 737 \\
\hline 1051.2 & 1062.5 & 1095.8 & 1281.1 \\
\hline 1152.8 & 1107.2 & 1128.0 & n.a. \\
\hline 989.0 & 960.6 & 999.2 & n.a. \\
\hline 538.9 & 529.9 & 539.5 & n.a. \\
\hline 1089.5 & 1160.4 & 1147.1 & 619.7 \\
\hline 1102.3 & 1289.8 & 1093.9 & n.a. \\
\hline 1480.1 & 1494.6 & 1480.2 & 571.3 \\
\hline 554.3 & 540.7 & 553.9 & n.a. \\
\hline 547.3 & 560.8 & 573.0 & n.a. \\
\hline n.a. & -825.9 & 1961.2 & n.a. \\
\hline n.a. & 556.3 & 915.6 & n.a. \\
\hline n.a. & 562.9 & 964.9 & n.a. \\
\hline n.a. & 531.0 & 908.5 & n.a. \\
\hline n.a. & -851.2 & 1955.6 & n.a. \\
\hline n.a. & 537.6 & 957.8 & n.a. \\
\hline n.a. & 755.0 & 896.9 & n.a. \\
\hline n.a. & -627.2 & 1942.5 & n.a. \\
\hline n.a. & 636.0 & 1133.0 & n.a. \\
\hline n.a. & -746.2 & 2181.1 & n.a. \\
\hline n.a. & 610.7 & 892.5 & n.a. \\
\hline n.a. & 569.0 & 907.6 & n.a. \\
\hline n.a. & -813.2 & 1955.2 & n.a. \\
\hline n.a. & 575.5 & 956.9 & n.a. \\
\hline 1287.4 & 1262.0 & 1265.6 & n.a. \\
\hline n.a. & 1068.9 & 1486.6 & n.a. \\
\hline n.a. & 372.4 & 1576.8 & n.a. \\
\hline
\end{tabular}

$\begin{array}{llll}1180.4 & 1030.0 \quad 1123.5 & 1228.9\end{array}$


115 butylammonium formate

116 butyltrimethylammonium bis(trifluoromethylsulfonyl)imide

117 decyl(trimethyl)ammonium bis(trifluoromethylsulfonyl)imide

118 hexyltrimethylammonium bis[(trifluoromethyl)sulfonyl]amide

119 methyltrioctylammonium bis(trifluoromethylsulfonyl)imide

120 N,N-dimethyl-N-propyl-1-butanaminium 1,1,1-trifluoro-N[(trifluoromethyl)sulfonyl]methanesulfonamide

121 N,N-dimethyl-N-propyldecanaminium 1,1,1-trifluoro-N[(trifluoromethyl)sulfonyl]methanesulfonamide

122 N,N-dimethyl-N-propylhexanaminium 1,1,1-trifluoro-N[(trifluoromethyl)sulfonyl]methanesulfonamide

123 N-butyl-3-methylpyridinium dicyanamide

124 N-butyl-4-methylpyridinium tetrafluoroborate

125 N-octyl-3-methylpyridinium tetrafluoroborate

126 tetradecyltrihexylphosphonium bromide

127 triethyl-1-decanaminium bis(trifluoromethylsulfonyl)imide

128 triethyl-1-dodecanammonium bis(trifluoromethylsulfonyl)imide

129 triethyl-1-pentylammonium bis(trifluoromethylsulfonyl)imide

130 triethylhexylammonium bis(trifluoromethylsulfonyl)imide

131 triethyloctylammonium bis(trifluoromethylsulfonyl)imide

132 trihexyl(tetradecyl)phosphonium bis[(trifluoromethyl)sulfonyl]imide

133

134

trihexyl(tetradecyl)phosphonium chloride

135 trihexyl(tetradecyl)phosphonium

tris(pentafluoroethyl)trifluorophosphate

136 trihexyltetradecylphosphonium bis(2,4,4-trimethylpentyl)phosphinate

137 trihexyltetradecylphosphonium decanoate

138 trihexyltetradecylphosphonium dicyanamide

139

trihexyltetradecylphosphonium methanesulfonate

\begin{tabular}{|c|c|c|c|}
\hline n.a. & 1441.2 & 1093.4 & 546.7 \\
\hline 1007.7 & 1052.9 & 1013.6 & 1038.7 \\
\hline 935.1 & 914.8 & 815.9 & 1136.3 \\
\hline 982.4 & 1043.2 & 1102.4 & 1173.9 \\
\hline 753.7 & 746.7 & 696.0 & n.a. \\
\hline 1111.9 & 947.7 & 991.5 & n.a. \\
\hline 818.9 & 726.3 & 888.0 & n.a. \\
\hline 879.6 & 907.1 & 918.3 & n.a. \\
\hline 721.1 & 875.6 & 802.1 & n.a. \\
\hline 1300.4 & 1147.6 & 1150.8 & 625.8 \\
\hline 698.1 & 757.6 & 753.4 & n.a. \\
\hline 846.9 & 895.9 & 843.3 & n.a. \\
\hline 751.9 & 765.3 & 756.0 & n.a. \\
\hline 727.2 & 740.0 & 732.4 & n.a. \\
\hline 902.7 & 916.0 & 894.0 & 1102.5 \\
\hline 813.2 & 806.7 & 847.5 & 1119.2 \\
\hline 775.8 & 819.7 & 775.9 & 1153.7 \\
\hline 869.5 & 892.7 & 870.7 & n.a. \\
\hline 819.7 & 895.9 & 855.6 & n.a. \\
\hline 916.4 & 875.9 & 867.3 & n.a. \\
\hline 945.9 & 839.7 & 804.3 & n.a. \\
\hline 784.1 & 783.7 & 805.9 & n.a. \\
\hline 864.4 & 842.9 & 842.3 & n.a. \\
\hline 831.2 & 875.9 & 867.3 & n.a. \\
\hline 842.3 & 821.0 & 943.5 & n.a. \\
\hline
\end{tabular}

